\title{
A CFD approach on the effect of particle size on char entrainment in bubbling fluidised bed reactors
}

\author{
K. Papadikis ${ }^{a}$, S. Gu ${ }^{b, *}$, A.V. Bridgwater ${ }^{a}$ \\ a School of Engineering and Applied Science, Aston University, Aston Triangle, Birmingham B4 7ET, United Kingdom \\ ${ }^{\mathrm{b}}$ School of Engineering Sciences, University of Southampton, Highfield, Southampton, SO17 1BJ, United Kingdom
}

\section{A R T I C L E I N F O}

Article history:

Received 22 June 2008

Received in revised form

31 August 2009

Accepted 28 September 2009

Available online 25 October 2009

Keywords:

CFD

Fluidized bed

Momentum transport

Char entrainment

\begin{abstract}
A B S T R A C T
The fluid - particle interaction inside a $41.7 \mathrm{mg} \mathrm{s}^{-1}$ fluidised bed reactor is modelled. Three char particles of sizes $500 \mu \mathrm{m}, 250 \mu \mathrm{m}$, and $100 \mu \mathrm{m}$ are injected into the fluidised bed and the momentum transport from the fluidising gas and fluidised sand is modelled. Due to the fluidising conditions and reactor design the char particles will either be entrained from the reactor or remain inside the bubbling bed. The particle size is the factor that differentiates the particle motion inside the reactor and their efficient entrainment out of it. A 3-Dimensional simulation has been performed with a completele revised momentum transport model for bubble three-phase flow according to the literature as an extension to the commercial finite volume code FLUENT 6.2.
\end{abstract}

๑ 2009 Elsevier Ltd. All rights reserved.

\section{Introduction}

Fluidised beds are the most widely used type of reactor for fast pyrolysis, as they offer a number of advantages, such as high heat transfer rates and good temperature control. The hydrodynamics of fluidised beds have been widely investigated, both experimentally and numerically, to allow validation of the model results. To date most of the computational research interest has been focused on the simulation of the fluidised bed hydrodynamics, using either the Eulerian (continuum) [1,2] or the Lagrangian (discrete element) $[3,4]$ model, as well as novel models like the one developed by [5] which is based on the modelling of the larger bubbles as discrete elements that are tracked individually during their rise through the emulsion phase, which is considered as a continuum. Due to the significant increase in computing power of recent years, these models have now made computational modelling of multiphase granular flows possible, though it is still very challenging, particularly so for industrial scale reactor units.

The Eulerian formulation of the granular medium, using the kinetic theory of granular flows, has made the realisation of fluidised bed simulations, less computationally intensive. The particulate phase is treated as a continuum with an effective viscosity, and thus the method is also called two-fluid approach. The drag force on a single spherical particle has been widely studied e.g. [6] and [7]. However, when a single particle moves in a dispersed two-phase flow, the drag force is affected by the surrounding particles. Correlations for calculating the momentum exchange coefficient of gas-solid systems have been reported in the literature, such as the models of [8-10].

Compared to two-phase flows that have been widely studied [11-14], the information for bubble three-phase flows is limited $[14,15]$. The calculation of drag forces on particles that are part of a solid/liquid/gas mixture is a more complicated

\footnotetext{
* Corresponding author. Tel.: +44 238059 8520; fax: +44 2380593230.

E-mail address: s.gu@soton.ac.uk (S. Gu). 


\begin{tabular}{|c|c|c|c|}
\hline \multicolumn{2}{|c|}{ Nomenclature } & $\lambda_{\mathrm{i}}$ & bulk viscosity, $\mathrm{kgs}^{-1} \mathrm{~m}^{-1}$ \\
\hline $\mathrm{C}_{\mathrm{D}}$ & drag coefficient, dimensionless & $\mu_{\mathrm{i}}$ & shear viscosity, $\mathrm{kgs}^{-1} \mathrm{~m}^{-1}$ \\
\hline$d_{\mathrm{i}}$ & diameter, $m$ & $\rho_{\mathrm{i}}$ & density, $\mathrm{kgm}^{-3}$ \\
\hline & diameter, $\mathrm{m}$ & $\tau_{\mathrm{v}}$ & velocity response time, $\mathrm{s}$ \\
\hline $\begin{array}{l}D \\
e_{\mathrm{cc}}\end{array}$ & $\begin{array}{l}\text { aroplet diameter, } \mathrm{m} \\
\text { restitution coefficient dimensionless }\end{array}$ & \multicolumn{2}{|c|}{$\overline{\bar{\tau}}_{i}$ stresses tensor, $\mathrm{Pa}$} \\
\hline $\begin{array}{l}\text { ess } \\
g\end{array}$ & gravitational acceleration, $\mathrm{ms}^{-2}$ & $\varphi_{\mathrm{gs}}$ & transfer rate of kinetic energy, $\mathrm{kgs}^{-3} \mathrm{~m}^{-1}$ \\
\hline$g_{0, \mathrm{ss}}$ & radial distribution coefficient, dimensionless & \multicolumn{2}{|c|}{ Subscripts } \\
\hline$\overline{\bar{I}}$ & stress tensor, dimensionless & 100 & $100 \mu \mathrm{m}$ diameter particle \\
\hline$I_{2 \mathrm{D}}$ & $\begin{array}{l}\text { second invariant of the deviatoric stress tensor, } \\
\text { dimensionless }\end{array}$ & $\begin{array}{l}250 \\
500\end{array}$ & $250 \mu \mathrm{m}$ diameter particle \\
\hline$f$ & drag factor, dimensionless & c & continuous phase \\
\hline$F_{\mathrm{i}}$ & force, $\mathrm{N} \mathrm{kg}^{-1}$ & col & collision \\
\hline$k_{\Theta s}$ & diffusion coefficient for granular energy, $\mathrm{kgs}^{-1} \mathrm{~m}^{-1}$ & $\mathrm{~d}$ & droplet \\
\hline$K_{\mathrm{gs}}$ & $\begin{array}{l}\text { gas/solid momentum exchange coefficient, } \\
\text { dimensionless }\end{array}$ & $\begin{array}{l}\mathrm{D} \\
\mathrm{dm}\end{array}$ & $\begin{array}{l}\text { Drag } \\
\text { disperse phase maximum packing }\end{array}$ \\
\hline$p$ & pressure, $\mathrm{Pa}$ & eff & effective \\
\hline$r$ & radial coordinate, $\mathrm{m}$ & fr & frictional \\
\hline$R$ & universal gas constant, $\mathrm{Jmol}^{-1} \mathrm{~K}^{-1}$ & $\mathrm{~g}$ & gas \\
\hline $\operatorname{Re}$ & Reynolds number, dimensionless & $\mathrm{i}$ & general index \\
\hline$t$ & time, s & kin & kinetic \\
\hline$U_{0}$ & superficial gas velocity, $\mathrm{ms}^{-1}$ & $\mathrm{~m}$ & mixture \\
\hline$U_{\mathrm{t}}$ & particle terminal velocity, $\mathrm{ms}^{-1}$ & $\mathrm{mf}$ & minimum fluidisation \\
\hline$u_{\mathrm{i}}$ & velocity, $\mathrm{ms}^{-1}$ & $\mathrm{p}$ & particle \\
\hline$w_{\mathrm{i}}$ & free settling velocity, $\mathrm{ms}^{-1}$ & $\mathrm{~s}$ & solids \\
\hline \multicolumn{2}{|c|}{ Greek letters } & $\mathrm{T}$ & stress tensor \\
\hline$\gamma_{\Theta s}$ & collision dissipation of energy, $\mathrm{kgs}^{-3} \mathrm{~m}^{-1}$ & $t$ & terminal \\
\hline$\varepsilon_{\mathrm{i}}$ & volume fraction, dimensionless & $\mathrm{v}$ & velocity \\
\hline$\Theta_{\mathrm{i}}$ & granular temperature, $\mathrm{m}^{2} \mathrm{~s}^{-2}$ & $\mathrm{vm}$ & virtual mass \\
\hline
\end{tabular}

case and certain assumptions have to be made. Kolev [14] analyses the bubble three-phase flow by making the assumption that the solid particles are carried by the liquid or a gas/ liquid mixture or the gas alone, depending on the local volume fraction of each one of the continuous phases. His approach is adopted for the implementation of the model described in this paper.

Char entrainment from the bubbling fluidised bed is an important parameter for fast pyrolysis. The presence of char/ ash in a fast pyrolysis process catalyses the produced tars resulting in lower bio-oil yields. The current paper applies the momentum transport model previously developed by the authors [16] to different size char particles inside the bubbling bed and examines their behaviour as well as residence time inside the reactor. The model can be efficiently applied as a guide for bubbling fluidised bed reactor design, where char entrainment is extremely important and investigate the effect of particle sizes and reactor geometry in the trajectories of the pyrolysed biomass particles.

\section{Model description}

The $41.7 \mathrm{mg} \mathrm{s}^{-1}$ fast pyrolysis lab scale reactor of Aston University is illustrated in Fig. 1. Nitrogen flows through a porous plate at the bottom of the reactor at a velocity of $U_{0}=0.3 \mathrm{~m} \mathrm{~s}^{-1}$. The superficial velocity is approximately 4 times greater than the minimum fluidising velocity $U_{\mathrm{mf}}$ of the reactor, which is typically around $0.08 \mathrm{~m} \mathrm{~s}^{-1}$ using a sand bed with average particle diameter of $440 \mu \mathrm{m}$ Geldart B Group [17].

Three char particles of average density of $200 \mathrm{~kg} \mathrm{~m}^{-3}$ are injected at different points of the the sand bed which has been previously fluidised for $0.5 \mathrm{~s}$. Momentum is transferred from the bubbling bed to the char particles as well as from the

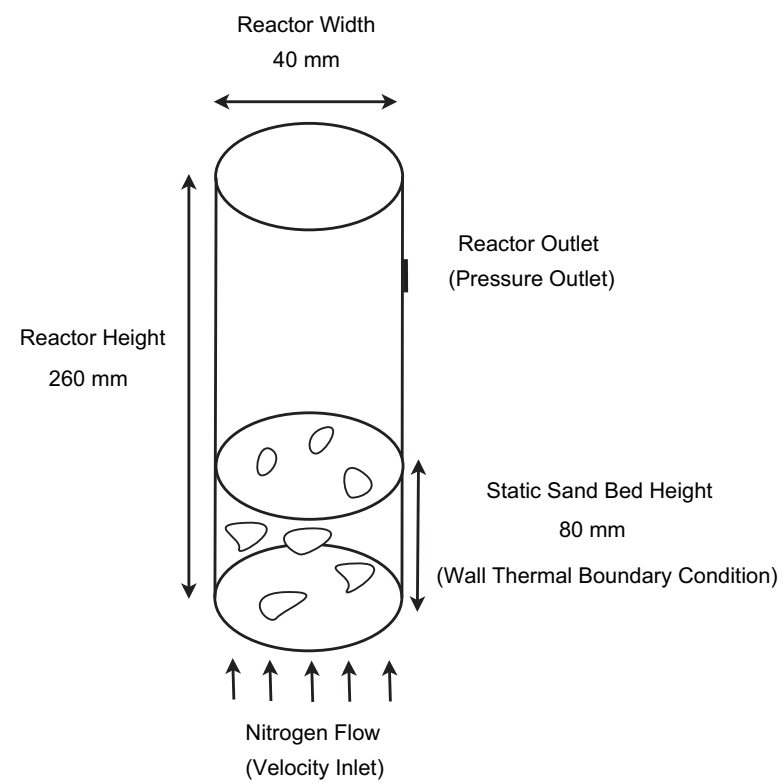

Fig. 1 - Fluidised bed reactor. 
formed bubbles inside the bed. According to Bridgwater [18], the most appropriate biomass particles sizes for liquid fuel production lie in the range of $100-6000 \mu \mathrm{m}$ with temperature between 700 and $800 \mathrm{~K}$. Thus, the studied char particles were chosen to be $500 \mu \mathrm{m}, 250 \mu \mathrm{m}$ and $100 \mu \mathrm{m}$ in diameter, which is more or less the size of the particles, due to feeding problems, for a small rig like the one studied in this paper. Bigger rigs and commercial plants use larger particles in the range of $2-5 \mathrm{~mm}$.

The scope of the simulation is to determine the correct momentum transport inside the reactor and to visualise the effect of the different size char particles on their entrainment from the reactor. The model will monitor the trajectories of the individual char particles will identify their instantaneous velocities, in comparison to the bubbling behaviour of the bed. When the particles are injected inside the reactor, they can either be inside a bubble or inside the packed bed. The code will be able to identify the regime of interest, depending on the local volume fraction of the two continuous phases, and calculate the correct drag, buoyancy and virtual mass forces according to the state. The simulation will show how the smaller and lighter particles will be entrained from the reactor while the larger and heavier ones will stay in the fluidised bed. By visualising these phenomena the engineer will be able to optimise the reactor design according to the needs of the studied process by knowing the range of biomass particle sizes that will be efficiently elutriated at the end of their pyrolysis. The aspect of biomass pyrolyzing is not included in this simulation while relevant information can be found in our previous work [19]. The performed simulation is 3-Dimensional and the reader is referred to the study of [16] for the complete analysis of the momentum transport model equations.

\section{Mathematical model}

\subsection{Multiphase flow governing equations}

The simulations of the bubbling behaviour of the fluidised bed were performed by solving the equations of motion of a multifluid system. An Eulerian model for the mass and momentum for the gas (nitrogen) and fluid phases, was applied, while the kinetic theory of granular flow, was applied for the conservation of the solid's fluctuation energy. The Eulerian model is already incorporated in the main code of FLUENT and its governing equations are expressed in the following form.

\subsubsection{Mass conservation}

Eulerian-Eulerian continuum modelling is the most commonly used approach for fluidized bed simulations. The accumulation of mass in each phase is balanced by the convective mass fluxes. The phases are able to interpenetrate and the sum of all volume fractions in each computational cell is unity.

gas phase:

$\frac{\partial\left(\varepsilon_{\mathrm{g}} \rho_{\mathrm{g}}\right)}{\partial \mathrm{t}}+\nabla \cdot\left(\varepsilon_{\mathrm{g}} \rho_{\mathrm{g}} \mathrm{v}_{\mathrm{g}}\right)=0$, solid phase:

$\frac{\partial\left(\varepsilon_{\mathrm{s}} \rho_{\mathrm{s}}\right)}{\partial \mathrm{t}}+\nabla \cdot\left(\varepsilon_{\mathrm{s}} \rho_{\mathrm{s}} v_{\mathrm{s}}\right)=0$.

\subsubsection{Momentum conservation}

Newton's second law of motion states that the change in momentum equals the sum of forces on the domain. In gassolid fluidised beds the sum of forces consists of the viscous force $\nabla \cdot \overline{\bar{\tau}}_{\mathrm{s}}$, the solids pressure force $\nabla p_{\mathrm{s}}$, the body force $\varepsilon_{\mathrm{s}} \rho_{\mathrm{s}} g$, the static pressure force $\varepsilon_{\mathrm{s}} \cdot \nabla p$ and the interphase force $K_{\mathrm{gs}}\left(u_{\mathrm{g}}-u_{\mathrm{s}}\right)$ for the coupling of gas and solid momentum equations by drag forces.

gas phase:

$$
\begin{aligned}
\frac{\partial\left(\varepsilon_{\mathrm{g}} \rho_{\mathrm{g}} \mathrm{v}_{\mathrm{g}}\right)}{\partial \mathrm{t}}+\nabla \cdot\left(\varepsilon_{\mathrm{g}} \rho_{\mathrm{g}} \mathrm{v}_{\mathrm{g}} \otimes \mathrm{v}_{\mathrm{g}}\right)= & -\varepsilon_{\mathrm{g}} \cdot \nabla p+\nabla \cdot \overline{\bar{\tau}}_{\mathrm{g}}+\varepsilon_{\mathrm{g}} \rho_{\mathrm{g} g} \\
& +K_{\mathrm{gs}}\left(\mathrm{u}_{\mathrm{g}}-\mathrm{u}_{\mathrm{s}}\right),
\end{aligned}
$$

solid phase:

$$
\begin{aligned}
\frac{\partial\left(\varepsilon_{\mathrm{s}} \rho_{\mathrm{s}} v_{\mathrm{s}}\right)}{\partial t}+\nabla \cdot\left(\varepsilon_{\mathrm{s}} \rho_{\mathrm{s}} \mathrm{v}_{\mathrm{s}} \otimes v_{\mathrm{s}}\right)= & -\varepsilon_{\mathrm{s}} \cdot \nabla p-\nabla p_{\mathrm{s}}+\nabla \cdot \overline{\bar{\tau}}_{\mathrm{s}}+\varepsilon_{\mathrm{s}} \rho_{\mathrm{s}} g \\
& +K_{\mathrm{gs}}\left(u_{\mathrm{g}}-u_{\mathrm{s}}\right),
\end{aligned}
$$

where the solid phase stress tensor is given by,

$\overline{\bar{\tau}}_{\mathrm{s}}=\varepsilon_{\mathrm{s}} \mu_{\mathrm{s}}\left(\nabla u_{\mathrm{s}}+\nabla u_{\mathrm{s}}^{\mathrm{T}}\right)+\varepsilon_{\mathrm{s}}\left(\lambda_{\mathrm{s}}-\frac{2}{3} \mu_{\mathrm{s}}\right) \nabla \cdot u_{\mathrm{s}} \overline{\bar{I}}_{\mathrm{s}}$,

and the Gidaspow interphase exchange coefficient,

$K_{\mathrm{gs}}=\frac{3}{4} C_{d} \frac{\varepsilon_{\mathrm{s}} \varepsilon_{\mathrm{g}} \rho_{\mathrm{g}}\left|u_{\mathrm{s}}-u_{\mathrm{g}}\right|}{d_{\mathrm{s}}} \varepsilon_{\mathrm{g}}^{-2.65}$ for $\varepsilon_{\mathrm{g}}>0.8$,

$K_{\mathrm{gs}}=150 \frac{\varepsilon_{\mathrm{s}}^{2} \mu_{\mathrm{g}}}{\varepsilon_{\mathrm{g}} d_{\mathrm{s}}^{2}}+1.75 \frac{\varepsilon_{\mathrm{s}} \rho_{\mathrm{g}}\left|u_{\mathrm{s}}-u_{\mathrm{g}}\right|}{d_{\mathrm{s}}}$ for $\varepsilon_{\mathrm{g}} \leq 0.8$,

where the drag coefficient is given by

$C_{\mathrm{d}}=\frac{24}{\varepsilon_{\mathrm{g}} R e_{\mathrm{s}}}\left[1+0.15\left(\varepsilon_{\mathrm{g}} R e_{\mathrm{s}}\right)^{0.687}\right]$

and

$R e_{\mathrm{s}}=\frac{d_{\mathrm{s}} \rho_{\mathrm{g}}\left|u_{\mathrm{s}}-u_{\mathrm{g}}\right|}{\mu_{\mathrm{g}}}$.

The bulk viscosity $\lambda_{\mathrm{s}}$ is a measure of the resistance of a fluid to compression which is described with the help of the kinetic theory of granular flows

$\lambda_{\mathrm{s}}=\frac{4}{3} \varepsilon_{\mathrm{s}} \rho_{\mathrm{s}} d_{\mathrm{s}} g_{0, \mathrm{ss}}\left(1+e_{\mathrm{ss}}\right) \sqrt{\frac{\Theta_{\mathrm{s}}}{\pi}}$.

The tangential forces due to particle interactions are summarised in the term called solids shear viscosity, and it is defined as

$\mu_{\mathrm{s}}=\mu_{\mathrm{s}, \mathrm{col}}+\mu_{\mathrm{s}, \mathrm{kin}}+\mu_{\mathrm{s}, \mathrm{rr}}$,

where the collision viscosity of the solids $\mu_{\mathrm{s} \text {, col }}$ is 
$\mu_{\mathrm{s}, \mathrm{col}}=\frac{4}{5} \varepsilon_{\mathrm{s}} \rho_{\mathrm{s}} d_{\mathrm{s}} g_{0, \mathrm{ss}}\left(1+e_{\mathrm{ss}}\right) \sqrt{\frac{\Theta_{\mathrm{s}}}{\pi}}$,

the frictional viscosity

$\mu_{\mathrm{s}, \mathrm{fr}}=\frac{p_{\mathrm{s}} \sin \left(\phi_{\mathrm{gs}}\right)}{2 \sqrt{I_{2 \mathrm{D}}}}$

and the Gidaspow [9] kinetic viscosity

$\mu_{\mathrm{s}, \mathrm{kin}}=\frac{10 \rho_{\mathrm{s}} d_{\mathrm{s}} \sqrt{\Theta_{\mathrm{s}} \pi}}{96 \varepsilon_{\mathrm{s}} g_{0, \mathrm{ss}}\left(1+e_{\mathrm{ss}}\right)} \times\left[1+\frac{4}{5} \varepsilon_{\mathrm{s}} g_{0, \mathrm{ss}}\left(1+e_{\mathrm{ss}}\right)\right]^{2}$.

The solids pressure $p_{\mathrm{s}}$, which represents the normal force due to particle interactions, and the transfer of kinetic energy $\varphi_{\mathrm{gs}}$ are given by

$p_{\mathrm{s}}=\varepsilon_{\mathrm{s}} \rho_{\mathrm{s}} \Theta+2 \rho_{\mathrm{s}}\left(1+e_{\mathrm{ss}}\right) \varepsilon_{\mathrm{s}}^{2} g_{0, \mathrm{ss}} \Theta_{\mathrm{s}}$

and

$\phi_{\mathrm{gs}}=-3 \mathrm{~K}_{\mathrm{gs}} \Theta_{\mathrm{s}}$.

\subsubsection{Fluctuation energy conservation of solid particles}

The solid phase models discussed above are based on two crucial properties, namely the radial distribution function $g_{0, \mathrm{ss}}$ and granular temperature $\Theta_{\mathrm{s}}$. The radial distribution function is a measure for the probability of interparticle contact. The granular temperature represents the energy associated with the fluctuating velocity of particles.

$$
\begin{aligned}
\frac{3}{2}\left[\frac{\partial}{\partial t}\left(\varepsilon_{\mathrm{s}} \rho_{\mathrm{s}} \Theta_{\mathrm{s}}\right)+\nabla \cdot\left(\varepsilon_{\mathrm{s}} \rho_{\mathrm{s}} u_{\mathrm{s}} \Theta_{\mathrm{s}}\right)\right] & =\left(-p_{\mathrm{s}} \overline{\bar{I}}_{\mathrm{s}}+\overline{\bar{\tau}}_{\mathrm{s}}\right) \\
& : \nabla \cdot u_{\mathrm{s}}+\nabla \cdot\left(k_{\Theta \mathrm{s}} \cdot \nabla \cdot \Theta_{\mathrm{s}}\right)-\gamma_{\Theta \mathrm{s}} .
\end{aligned}
$$

where $\overline{\bar{\tau}}_{s}$ is defined in Eq. 5. The diffusion coefficient of granular temperature $k_{\Theta s}$ according to [9] is given by:

$$
\begin{aligned}
k_{\Theta \mathrm{s}}= & \frac{150 \rho_{\mathrm{s}} d_{\mathrm{s}} \sqrt{\Theta_{\mathrm{s}} \pi}}{384\left(1+e_{\mathrm{ss}}\right) g_{0, \mathrm{ss}}} \\
& {\left[1+\frac{6}{5} \varepsilon_{\mathrm{s}} g_{0, \mathrm{ss}}\left(1+e_{\mathrm{ss}}\right)\right]^{2}+2 \rho_{\mathrm{s}} d_{\mathrm{s}} \varepsilon_{\mathrm{s}}^{2} g_{0, \mathrm{ss}}\left(1+e_{\mathrm{ss}}\right) \sqrt{\frac{\Theta_{\mathrm{s}}}{\pi}} . }
\end{aligned}
$$

The radial distribution function $g_{0, \text { ss }}$ is defined as

$g_{0, \mathrm{ss}}=\left[1-\left(\frac{\varepsilon_{\mathrm{s}}}{\varepsilon_{\mathrm{s}, \max }}\right)^{1 / 3}\right]^{-1}$

and the collision dissipation energy as

$\gamma_{\Theta \mathrm{s}}=\frac{12\left(1-e_{\mathrm{ss}}^{2}\right) g_{0, \mathrm{ss}}}{d_{\mathrm{s}} \sqrt{\pi}} \rho_{\mathrm{s}} \varepsilon_{\mathrm{s}}^{2} \Theta_{\mathrm{s}}^{3 / 2}$.

An analytical discussion of the solid phase properties can be found on [20].

\subsection{Forces on discrete particles}

The coupling between the continuous and discrete phases has been developed in a UDF to take into account the bubbling behaviour of the bed. For an analytical discussion of this section the reader is referred on the previous work done by the authors in this aspect [16]. Assuming a spherical droplet with material density of $\rho_{\mathrm{d}}$ inside a fluid, the rate of change of its velocity can be expressed as [22] $\frac{\mathrm{d} u_{\mathrm{d}}}{\mathrm{dt}}=\frac{f}{\tau_{\mathrm{u}}}\left(u_{\mathrm{c}}-u_{\mathrm{d}}\right)+g\left(1-\frac{\rho_{\mathrm{c}}}{\rho_{\mathrm{d}}}\right)+F_{\mathrm{vm}}$,

where $f$ is the drag factor and $\tau_{\mathrm{u}}$ the velocity response time

$\tau_{\mathrm{u}}=\frac{\rho_{\mathrm{d}} D^{2}}{18 \mu_{\mathrm{c}}}$.

There are several correlations for the drag factor $f$ in the literature [23-25]. The one used in this study is the correlation of Putnam [25]

$f=1+\frac{R e_{r}^{(2 / 3)}}{6}$ for $R e_{r}<1000$

$f=0.0183 \operatorname{Re}_{\mathrm{r}}$ for $1000 \leq \operatorname{Re}_{\mathrm{r}}<3 \times 10^{5}$.

The second term on the right hand side of the equation represents the gravity and buoyancy force, while the third term represents the unsteady force of virtual mass force which is expressed as

$F_{\mathrm{vm}}=\frac{\rho_{\mathrm{c}} \mathrm{V}_{\mathrm{d}}}{2}\left(\frac{\mathrm{d} u_{\mathrm{c}}}{\mathrm{dt}}-\frac{\mathrm{d} u_{\mathrm{d}}}{\mathrm{dt}}\right)$

According to Kolev [14], if bubble three-phase flow (i.e. solid particles in bubbly flow) is defined, two sub-cases are distinguished. If the volume fraction of the space among the solid particles, if they were closely packed is smaller than the liquid fraction (in this case the Eulerian sand, fig. 2)

$\varepsilon_{\mathrm{s}}^{*}<\varepsilon_{\mathrm{s}}$

where

$\varepsilon_{\mathrm{s}}^{*}=\frac{1-\varepsilon_{\mathrm{dm}}}{\varepsilon_{\mathrm{dm}}} \varepsilon_{\mathrm{d}}$

then the theoretical possibility exists that the particles are carried only by the liquid. The hypothesis is supported if we consider the ratio of the free setting velocity in gas and liquid

$\frac{w_{\mathrm{dg}}}{w_{\mathrm{ds}}}=\sqrt{\frac{\rho_{\mathrm{d}}-\rho_{\mathrm{g}}}{\rho_{\mathrm{d}}-\rho_{\mathrm{s}}} \frac{\rho_{\mathrm{s}}}{\rho_{\mathrm{g}}}} \gg 1$.

Due to great differences between gas and liquid densities, the particles sink much faster in gas than in a liquid. Therefore, the drag force between gas and solid particle is zero and the drag force between solid and liquid is computed for a modified particle volume fraction $\varepsilon_{\mathrm{p}}$

$\varepsilon_{\mathrm{p}}=\frac{\varepsilon_{\mathrm{d}}}{\varepsilon_{\mathrm{s}}+\varepsilon_{\mathrm{d}}}$

and an effective continuum viscosity $\mu_{\text {eff, c }}$

$\mu_{\text {eff }, \mathrm{c}}=\left(1-\frac{\varepsilon_{\mathrm{p}}}{\varepsilon_{\mathrm{dm}}}\right)^{-1.55}$.

If the volume fraction of the space among the solid particles, if they were closely packed is larger than the liquid fraction

$\varepsilon_{\mathrm{s}}^{*}>\varepsilon_{\mathrm{s}}$,

then only

$\varepsilon_{\mathrm{dg}}=\varepsilon_{\mathrm{d}}\left(1-\varepsilon_{\mathrm{s}} / \varepsilon_{\mathrm{s}}^{*}\right)$ 

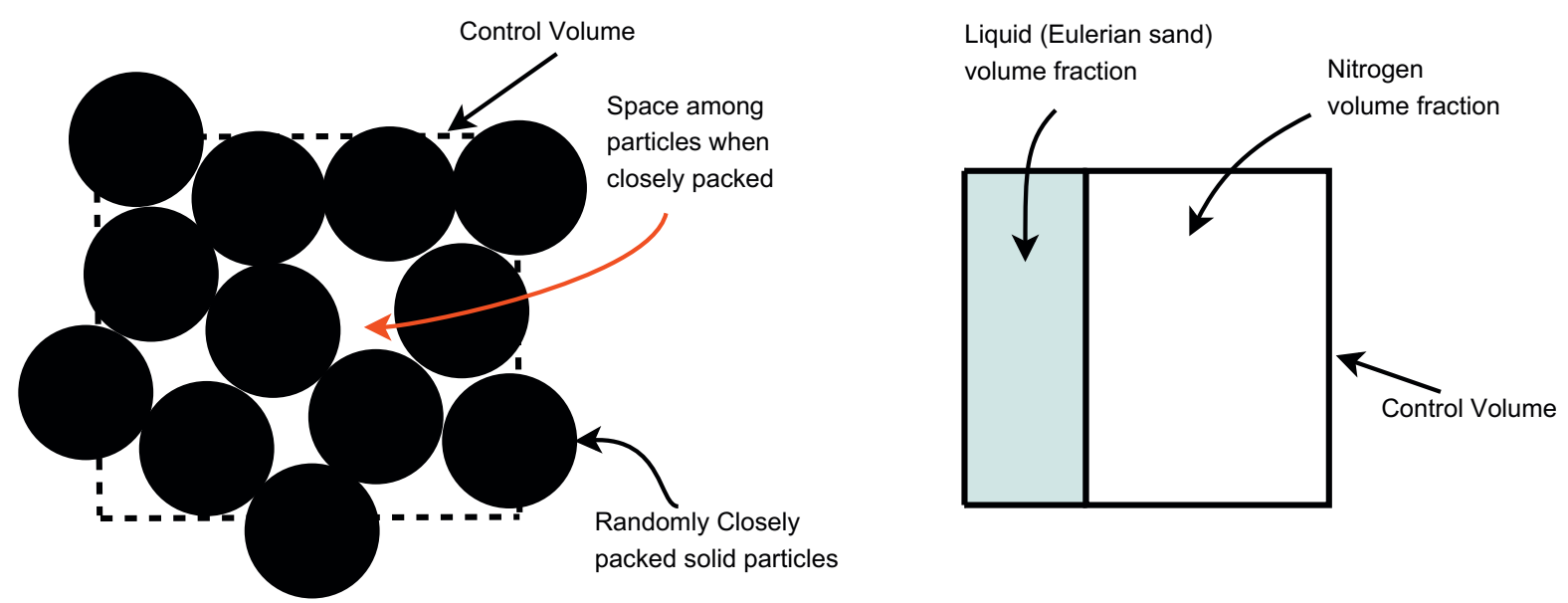

Fig. 2 - Left: Random close packing of spheres in a control volume $\varepsilon \approx 63 \%$, Right: Volume fraction of continuous phases in a control volume.

are surrounded by gas and the drag force can be calculated between one single solid particle and gas as for a mixture

$\varepsilon_{\mathrm{p}}=\frac{\varepsilon_{\mathrm{dg}}}{\varepsilon_{\mathrm{g}}+\varepsilon_{\mathrm{dg}}}$.

\section{Model parameters and assumptions}

For the implementation of the simulation certain parameters have to be quantified and assumption be made. Table 1 defines the basic material properties and parameters of the simulation. The most important parameters and assumptions are listed below.

- The particles used in the simulation were assumed to be totally spherical, whereas the particles used in experiments can be found on all sorts of shapes. The actual sphericity of the particles greatly differs from 1 . This would have an

\begin{tabular}{|c|c|c|}
\hline Property & Value & Comment \\
\hline Reactor central axis, & $(0.0,0.0,0.0)$ & $\begin{array}{l}\text { Along the height } \\
\text { of the reactor }\end{array}$ \\
\hline $500 \mu \mathrm{m}$ particle, & $(0.0,0.04,0.0)$ & Centre of sand bed \\
\hline $250 \mu \mathrm{m}$ particle, & $(0.01,0.06,0.01)$ & $\begin{array}{l}\text { Random point } \\
\text { at the sand bed }\end{array}$ \\
\hline $100 \mu \mathrm{m}$ particle, & $(0.005,0.05,-0.01)$ & $\begin{array}{l}\text { Random point } \\
\text { at the sand bed }\end{array}$ \\
\hline Gas density, $\rho_{\mathrm{g}}$ & $456 \mathrm{gm}^{-3}$ & Nitrogen $(773 \mathrm{~K})$ \\
\hline Gas viscosity, $\mu_{\mathrm{g}}$ & $34.4 \mathrm{mg} \mathrm{m}^{-1} \mathrm{~s}^{-1}$ & Nitrogen $(773 \mathrm{~K})$ \\
\hline $\begin{array}{l}\text { Solids particle } \\
\text { density, } \rho_{\mathrm{s}}\end{array}$ & $2.5 \mathrm{Mg} \mathrm{m}^{-3}$ & Sand \\
\hline $\begin{array}{l}\text { Mean solids } \\
\text { particle diameter, } d_{\mathrm{s}}\end{array}$ & $440 \mu \mathrm{m}$ & Uniform distribution \\
\hline Restitution coefficient, $e_{\mathrm{ss}}$ & 0.9 & Value in literature \\
\hline $\begin{array}{l}\text { Initial solids } \\
\text { packing, } \varepsilon_{\mathrm{s}}\end{array}$ & 0.63 & Fixed value \\
\hline Static bed height & $0.08 \mathrm{~m}$ & Fixed value \\
\hline Bed width & $0.04 \mathrm{~m}$ & Fixed value \\
\hline
\end{tabular}

impact on the drag and virtual mass forces and consequently on the trajectory of the particle inside the reactor.

- Three random positions were chosen for the char particles to be injected, in order to indicate the effect of the radial position of the particles on their trajectory.

- The model assumes a plug flow profile at the inlet of the reactor.

- The geometry of the reactor has been discretised using a structured grid. The average side length of the computational cells is about $1 \mathrm{~mm}$ resulting to a total number of 216,635 cells for the 3-Dimensional case with minimum cell volume of $9.25 \times 10^{10} \mathrm{~m}^{3}$, maximum cell volume of $3.3 \times 10^{-9} \mathrm{~m}^{3}$, and an equisize skewness of the worst element of 0.35 .

\section{Results and discussions}

Fig. 3 shows the bed hydrodynamics and relative particle positions at different times of the simulation in an isometric representation. Since it was impossible to capture all three particle positions at the isometric views of fig. 3 , slices across the sand bed at $0.02 \mathrm{~m}$ intervals were taken at time $t=1.0 \mathrm{~s}$ (fig. 4) to visualise the flight of the particles inside the reactor. The outlet of the reactor is also visible.

The simulation lasted for $1.5 \mathrm{~s}$ which means that the flight time of the particles was $1 \mathrm{~s}$ (injection of particles started at $0.5 \mathrm{~s}$ of the simulation). There are numerous correlations to determine the terminal velocity of a particle and the reader is referred to [21] for a detailed description. The particles were injected at random positions inside the reactor at $t=0.5 \mathrm{~s}$ and the momentum transport from the fluidised bed was calculated accoriding to [16]. However, when the particles were ejected from the bed to the freeboard of the reactor, the particles are carried only by the upward flowing gas stream. The terminal velocities of the three different size particles $(100 \mu \mathrm{m}, 250 \mu \mathrm{m}$, $500 \mu \mathrm{m}$ ) were calculated as $U_{\mathrm{t}_{100}}=0.032 \mathrm{~ms}^{-1}, U_{\mathrm{t}_{250}}=0.18 \mathrm{~ms}^{-1}$ and $U_{t_{500}}=0.57 \mathrm{~ms}^{-1}$ respectively. By examining the contours and vectors of the nitrogen velocity magnitude (fig. 5) in the freeboard of the reactor one can have an immediate impression 


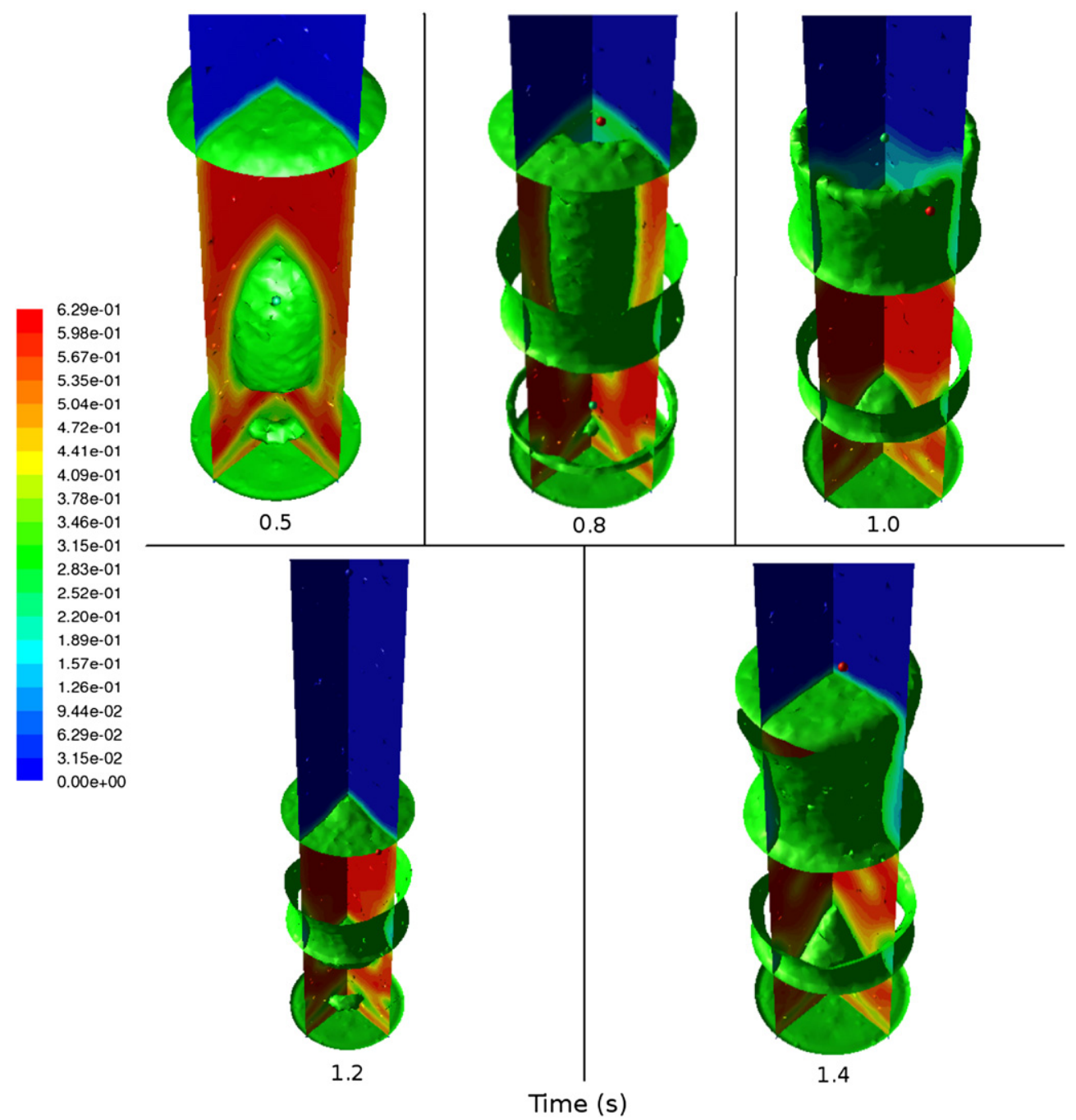

Fig. 3 - Fluidised bed hydrodynamics with particle positions. Nitrogen bubbles shown at 0.7 volume fraction.

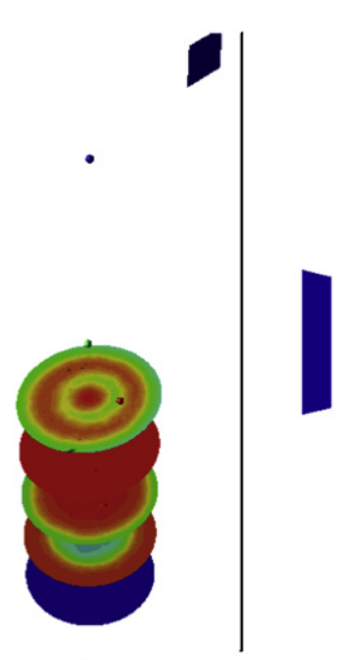

a

Time $=1.0$ second

Fig. 4 - Isometric (a) and top (b) view of the bed hydrodynamics (horizontal slices at $0.02 \mathrm{~m}$ intervals across the sand bed) with particle positions (blue: $100 \mu \mathrm{m}$, green: $250 \mu \mathrm{m}$, red: $500 \mu \mathrm{m}$ ) at $\mathrm{t}=\mathbf{1 . 0} \mathrm{s}$. Reactor outlet is visible. of which particle is going to be entrained from the reactor and which one is more likely to fall back into the bed.

The velocity magnitude of nitrogen in the freeboard of the reactor ranges from $\approx 0.25-3 \mathrm{~m} \mathrm{~s}^{-1}$. However, the maximum increase in velocity occurs close to the outlet of the reactor. The maximum velocity of nitrogen in the transport disengaging zone of the reactor only reaches $0.47 \mathrm{~m} \mathrm{~s}^{-1}$. In this specific region of the reactor the finer particles are separated from the larger ones and entrained from the reactor. By comparing the velocity of nitrogen and the terminal velocities of the three char particles that have been injected, we should expect the $100 \mu \mathrm{m}$ and $250 \mu \mathrm{m}$ particles to be entrained from the reactor while the $500 \mu \mathrm{m}$ to fall back into the bed and continue mixing with the sand particles.

Indeed, this is what is happening. Fig. 6 shows the velocity components for each particle. The $100 \mu \mathrm{m}$ and $250 \mu \mathrm{m}$ particles are entrained from the bed and consequently out of the reactor at $t=1.13 \mathrm{~s}$ and $t=1.30 \mathrm{~s}$ respectively, while the $500 \mu \mathrm{m}$ particle falls back into the bed. This can be seen by the increase in $\mathrm{x}$-velocity component of the $100 \mu \mathrm{m}$ and $250 \mu \mathrm{m}$ particles, which happens close to the outlet of the reactor where the nitrogen $\mathrm{x}$-velocity component becomes dominant and drag in the $\mathrm{x}$-direction is more intense. 


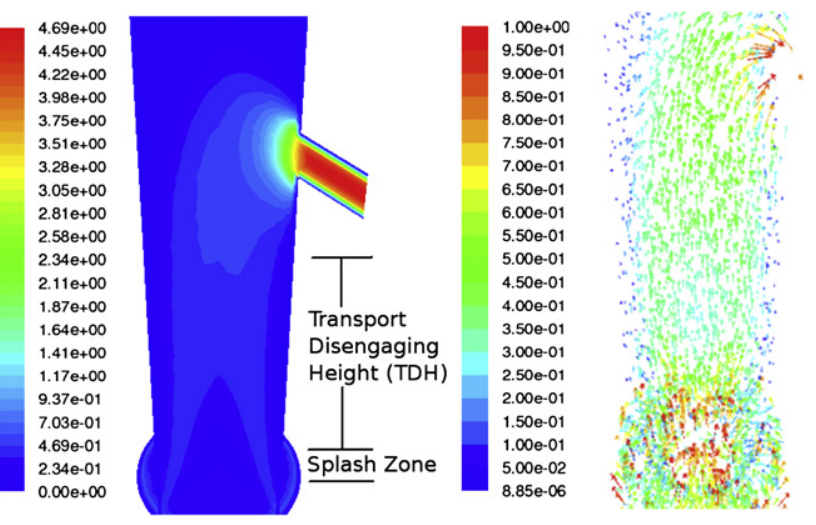

Fig. 5 - Contours (left) and vectors (right) of nitrogen velocity magnitude at the freeboard of the reactor.

Figs. 7-9 show the local nitrogen and sand velocity components for each particle as well as the local sand and nitrogen volume fractions. This is the way the code is able to identify the regime in which each particle is found as well as calculates the gravitational, buoyant, drag and virtual mass forces for each one of the particles. Fig. 10 shows the particle flights inside the reactor. The Cartesian coordinates refer to the reactor dimensions considering as centre the $(0,0,0)$ coordinate at the bottom of the reactor. The $100 \mu \mathrm{m}$ and $250 \mu \mathrm{m}$ particles are efficiently entrained from the reactor (reactor outlet $(0.02,0.21,0)$ ), while the $500 \mu \mathrm{m}$ one remains inside the bed.

Figs. 11 and 12 show the drag and virtual mass forces calculated for each particle in the 3-Dimensional space. The drag is the dominant force that moves the particles inside the reactor since its magnitude greatly exceeds the magnitude of the virtual mass force and it can reach up to $\approx 6000 \mathrm{~N} \mathrm{~kg}^{-1}$ as in the case of the $100 \mu \mathrm{m}$ particle at $t \approx 0.8 \mathrm{~s}$, where it finds itself inside a high sand concentration zone $(\approx 60 \%$ sand in fig. 9) moving with a velocity of $\approx 0.6 \mathrm{~m} \mathrm{~s}^{-1}$ (fig. 8). Virtual mass force is considered negligible when the particles are carried by the fluidising gas due to the great differences in gas and particle densities as it is shown in [16].

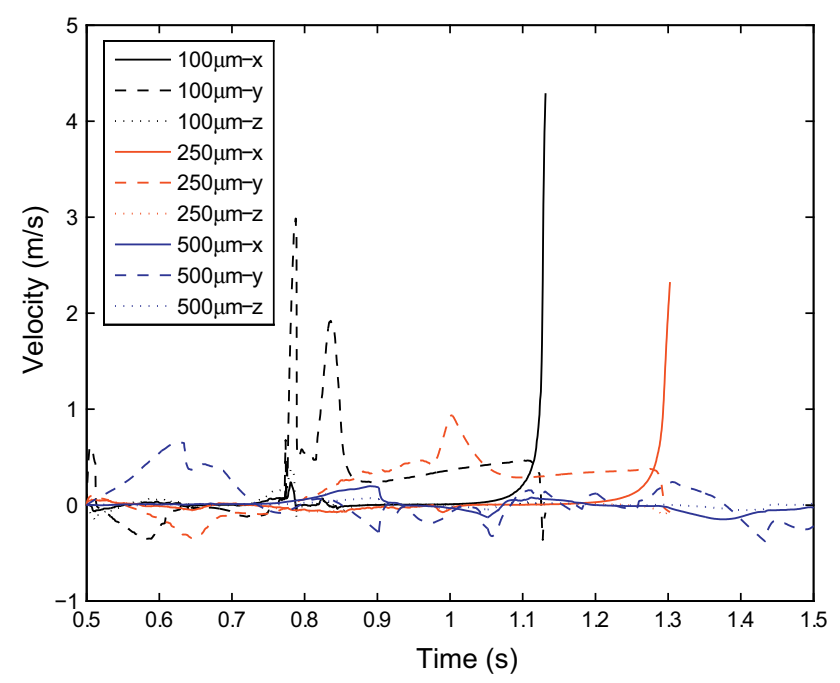

Fig. 6 - Velocities of the three char particles in the $x, y, z$ direction.

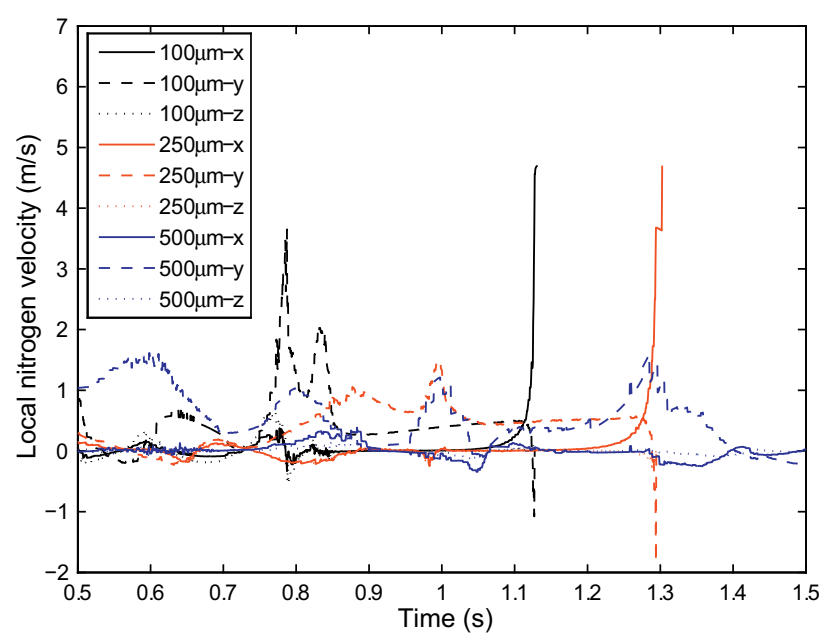

Fig. 7 - Local nitrogen velocity for each particle.

The studied fluidised bed comprises of solid sand grains which are fluidised from a gas to result in a fluid-like behaviour. Hence, momentum is transported in fluidised beds by collisions of sand grains with biomass particles together with the drag produced by the continuous phase (gas). The averaged approach (Eulerian-Eulerian) adopted in this paper for the behaviour of the sand, led to the representation of the collisional forces between the solid particles with drag functions associated with the fluid-like behaviour of the sand.

However, modelling of forces on particles inside a fluid flow is not an easy task. Steady and unsteady forces act on the particles due to the relative motion of fluids as well as rotational effects. In this study, the forces considered to act on the particle are the steady-state drag, the pressure gradient, buoyancy force and the virtual mass force. Rotational effects of the particle have not been considered, so lift forces (Saffman force, Magnus force) were assumed not to play a significant role. Also, sphericity effects were not considered since the particle was assumed to be totally spherical.

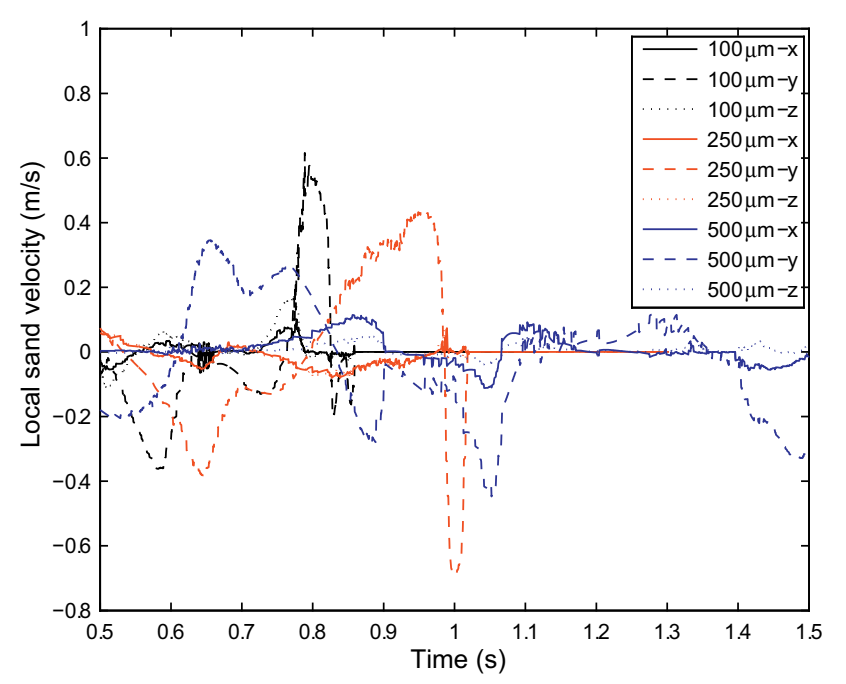

Fig. 8 - Local sand velocity for each particle. 


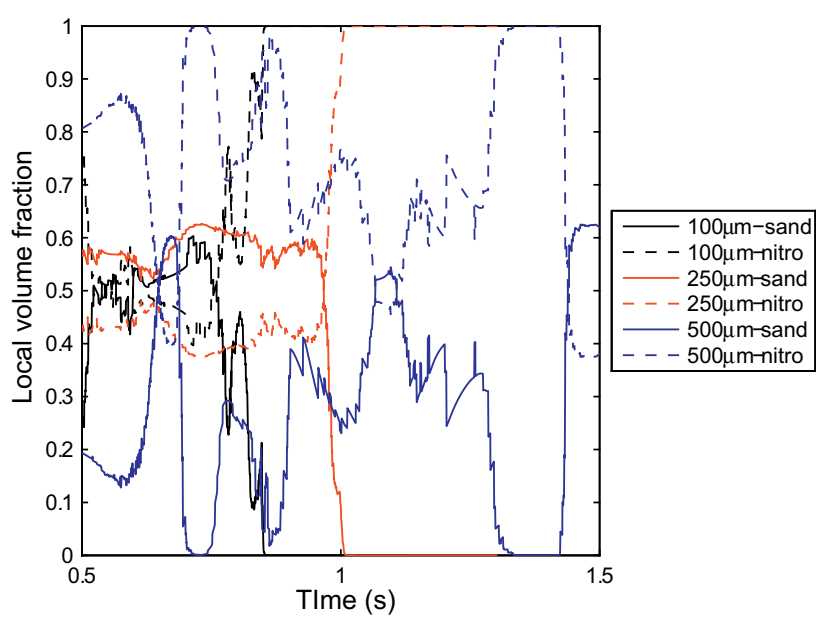

Fig. 9 - Local sand and nitrogen volume fraction.

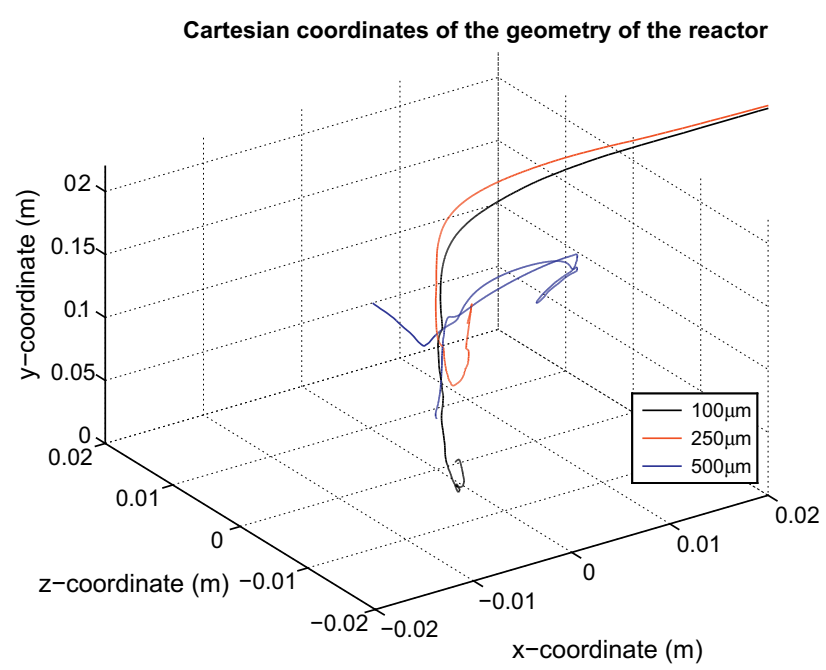

Fig. 10 - Particle positions in the 3-D space of the reactor.

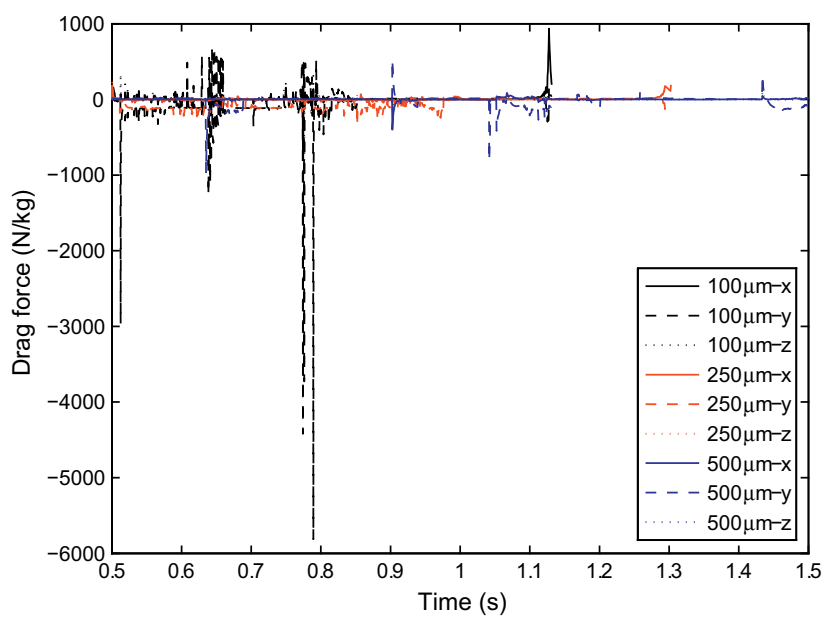

Fig. 11 - Drag force on the particles.

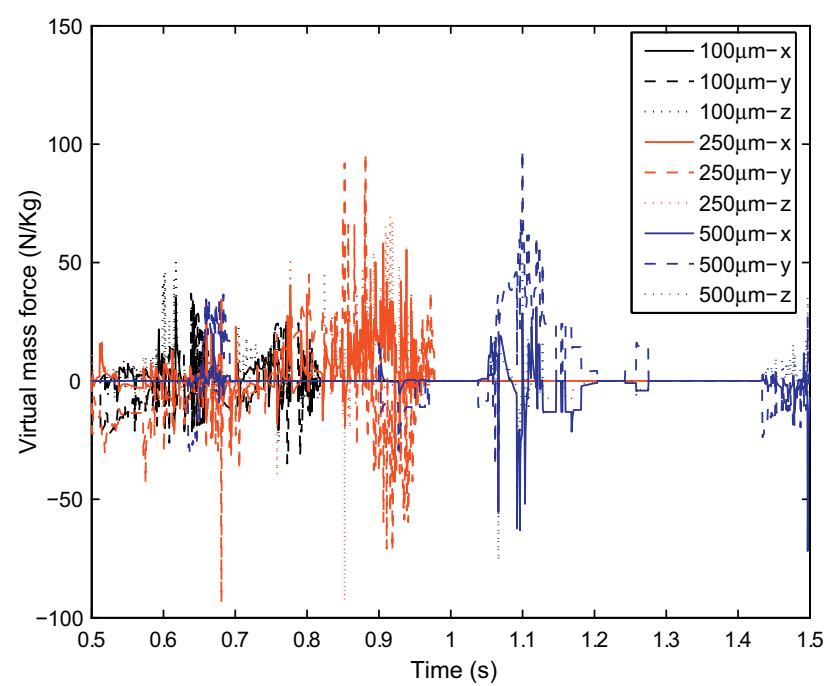

Fig. 12 - Virtual mass force on the particles.

However, the model accurately predicted the different size particle behaviour and entrainment inside the reactor using simple calculations. In fast pyrolysis processes, char particles need to efficiently be entrained from the reactor to avoid catalysis of produced tars. The model could be a good guide for fluidised bed reactor design since geometrical modifications can improve the reactor performance.

\section{Conclusions}

The momentum transport from the fluidised bed of a $41.7 \mathrm{mg} \mathrm{s}^{-1}$ lab scale reactor to three different size char particles $(100 \mu \mathrm{m}$, $250 \mu \mathrm{m}$ and $500 \mu \mathrm{m}$ ) was modelled. The paper used the model previously developed by the authors [16] to investigate char entrainment in bubbling fluidised bed reactors. It was shown that different size particles will result in different particle flights inside the reactors and that reactor design could be optimised by modifications guided by the simulations.

The paper showed that the current CFD model can be a good guide in the determination of the feedstock particle sizes that can be used in a specific type of reactor. Despite the fact that the complete pyrolysis process was not modelled in this case, the behaviour of the remaining char particles can indicate the size limits that the reactor can afford for efficient char and sand separation, which starts at the splash zone and ends at the freeboard of the reactor. The application of the current model can be extended to several other processes involving momentum transport from a bubbling phase such as combustion and gasification, by simple modifications in the User Defined Function.

Modelling of multiphase flows combined with discrete particle tracking can be possible by incorporating an external User defined function in a commercial CFD software. FLUENT 6.2 was used as the modelling framework for the simulation with an extensive computational sub-routine to account for the momentum transport from the fluidised bed to the char particle. 


\section{Acknowledgements}

The authors gratefully acknowledge the financial support from the EC FP7 Simuspray project (Grant No. 230715), the UK EPSRC (Grant No. EP/G034281/1) and Leverhulme-Royal Society Africa Award.

\section{R E F E R E N C E S}

[1] Pain CC, Mansoorzadeh S, Gomes JLM, de Oliveira CRE. A numerical investigation of bubbling gas-solid fluidized bed dynamics in 2-D geometries. Powder Technol 2002;128:56-77.

[2] Taghipour F, Ellis N, Wong C. Experimental and computational study of gas-solid fluidized bed hydrodynamics. Chem Eng Sci. 2005;60:6857-67.

[3] Hoomans BPB, Kuipers JAM, Briels WJ, Van Swaaij WPM. Discrete particle simulation of bubble and slug formation in a two-dimensional gas-fluidised bed: a hard-sphere approach. Chem Eng Sci 1996;51:99-118.

[4] Kafui KD, Thornton C, Adams MJ. Discrete particlecontinuum fluid modelling of gas-solid fluidised beds. Chem Eng Sci 2002;57:2395-410.

[5] Bokkers GA, Laverman JA, Van Sint Annaland M, Kuipers JAM. Modelling of large-scale dense gas-solid bubbling fluidised beds using a novel discrete bubble model. Chem Eng Sci 2006;61:5590-602.

[6] Clift R, Weber ME, Grace JR. Bubbles, drops, and particles. New York: Academic Press; 1978.

[7] Bird RB, Stewart WE, Lightfoot EN. In: Transport phenomena. 2nd ed. New York: Wiley; 2002.

[8] Syamlal M, O'Brien TJ. Computer simulation of bubbles in a fluidized bed. AIChE Symposium Series 1989;85:22-31.

[9] Gidaspow D. Multiphase flow and fluidization: continuum and kinetic theory descriptions. New York: Academic Press; 1994.
[10] Wen C-Y, Yu YH. Mechanics of fluidization. Chem Eng Prog Symposium Series 1966;62:100-11.

[11] Ishii M, Zuber N. Relative motion and interfacial drag coefficient in dispersed two-phase flows of bubbles, drops and particles, Paper 56 a, A.I.Ch.E 71st Ann. Meet. Miami; 1978.

[12] Ishii M, Chawla TC. Local drag laws in dispersed two-phase flow, NUREG/CR-1230 1975; ANL-79-105.

[13] Tomiyama A. Struggle with computational bubble dynamics. Lyon France: I.C.M.F; 1998.

[14] Kolev NI. In: Multiphase flow dynamics 2, thermal and mechanical interactions. 2nd ed. Springer; 2005.

[15] Sommerfeld M. Bubbly flows: analysis, modelling and calculation. Springer; 2004.

[16] Papadikis K, Bridgwater AV, Gu S. CFD modelling of the fast pyrolysis of biomass in fluidised bed reactors, part A: eulerian computation of momentum transport in bubbling fluidised beds. Chem Eng Sci 2008;63(16):4218-27.

[17] GeldartD. Types of gas fluidization. Powder Technol 1973;7:285.

[18] Bridgwater AV. Principles and practice of biomass fast pyrolysis processes for liquids. J Anal Appl Pyrolysis 1999;51: 3-22.

[19] Papadikis K, Gu S, Bridgwater AV. CFD modelling of the fast pyrolysis of biomass in fluidised bed reactors, part B: heat, momentum and mass transport in bubbling fluidised beds. Chem Eng Sci 2009;64(5):1036-45.

[20] Boemer A, Qi H, Renz U. Eulerian simulation of bubble formation at a jet in a two-dimensional fluidized beds. Int J Multiphase Flow 1997;23(5):927-44.

[21] Kunii D, Levenspiel O. In: Fluidization engineering. 2nd ed. Butterworth-Heinemann; 1991.

[22] Crowe CT, Sommerfield M, Tsuji Y. Multiphase flows with droplets and particles. CRC Press LLC; 1998.

[23] Schiller L, Naumann A. Uber die grundlegenden Berechungen bei der Schwerkraftaufbereitung. Ver Deut Ing; 77:318.

[24] Clift R, Gauvin WH. The motion of particles in turbulent gas streams. Proc Chemeca 1970;1:14.

[25] Putnam A. Integrable form of droplet drag coefficient. ARS JNl 1961;31:1467. 